\title{
Strategy for high stress environment in longwall entries
}

\author{
Baozhu Liu ${ }^{1, a}$, Jingli Zhao ${ }^{1, b}$ and Pengfei Wang ${ }^{1, c}$ \\ ${ }^{1}$ School of Resource and Safety Engineering, China University of Mining and Technology (Beijing), \\ Beijing, 100083, China \\ a2409908117@qq.com, b1007210351@qq.com, cshengshikuangdaren@163.com
}

\begin{abstract}
Longwall mining is the main method for coal extraction in China. However, development entry support on both ends of a longwall panel has always been a difficulty to cope with, especially in deep high stress conditions. In order to improve the stress environment for longwall entries, an innovative mining method called longwall mining with split-level gateroads (LMSG) is proposed in this paper. The entries on both ends of a LMSG panel are split-level, i.e., located at different height within a coal seam with a gradually elevated section on one end of the panel which make the two panels are offset. For the case study in this paper, the application of the method is extended to relatively thin coal seam to cope with problems in deep high stress conditions, that is, the headgate is driven in coal seam while the tailgate driven in roof strata. Mechanical tests and physical modeling were carried out and the results show that the stress environment is significantly improved.
\end{abstract}

Keywords: High stress, longwall entry, split-level, mechanical tests.

\section{Introduction}

As more easily mined coal deposits have been depleted, the reserves are more limited and deposits are less favorable. Many coal mines in Shandong province, P.R. China reached more than $1000 \mathrm{~m}$ resulting in very high ground pressure and difficulties in entry support. The principal method of underground coal extraction in China is longwall mining. The stability of gateroads is essential for the safety of longwall mines. A failure or collapse of gateroads may lead to fatality or interruption of mining operations and significant economic loss [1, 2]. Gateroads and chain pillars between longwall panels are subject to a complex loading process throughout their service life [3]. Only common support such as is not enough to prevent major roof falls from occurring in an uncontrollable fashion [4].

\section{Background}

When coal is extracted, stress uniformly distributed before excavation in the longwall panel will be re distribute until a new equilibrium is achieved, resulting in side abutments pressure within the solid coal and rock mass [5] as shown in Fig. 1.

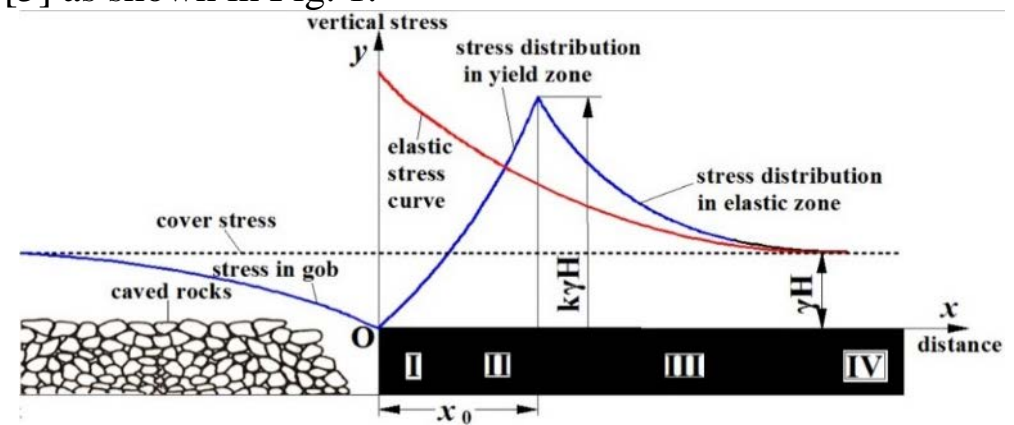

Fig. 1 Stress distribution after extraction of a longwall panel

Abutment pressure along the positive direction of $\mathrm{x}$ coordinate axis increases exponentially near the origin and reaches peak abutment pressure at a certain distance $x_{0}$. Then it decreases exponentially with the distance from the ribs. The solid coal on the right is divided into four zones: 
I-De-stressed plastic zone,II-Stress increasing elastic zone, III-Stress decreasing elastic zone, IV-Virgin cover load zone. The peak pressure can reach up to five times the original overburden pressure.

For decades, gateroads on both ends of a longwall panel are typically driven along the floor, namely they are within the same height (Fig. 2) which inevitably forces gateroads to be located in side abutment pressure zones (i.e., II or III zones in Fig. 1) due to chain pillars left unmined between panels causing support and maintenance problems in gateroads. Tailgate only a pillar width away from the mined-out panel will suffer from the concentrated pressure.

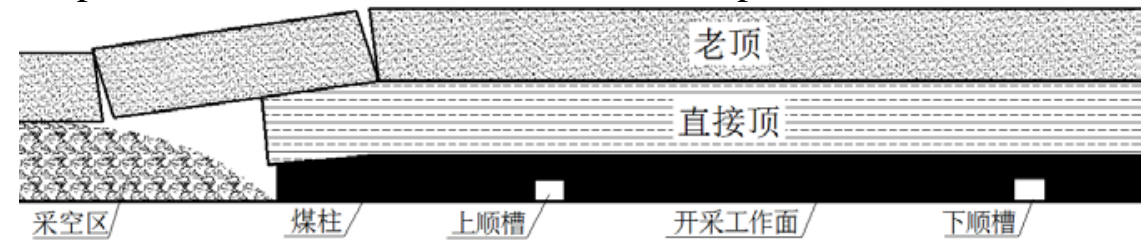

Fig. 2 Typical layout of longwall pane

Generally a huge chain pillar have to be left unmined between panels to avoid the influence of abutment pressure. Current chain pillar width in America is about $30 \mathrm{~m}$ and every one foot reduction in pillar width adds a very attractive incentive in today's high production longwalls [6]. In depth and high stress concentration area, pillar width is inevitably larger meaning lower recovery ratio. In addition, chain pillar causes many problems. First, high stress concentration that occurs in pillars often leads to the deterioration of their size, stability and supportive function. And progressively smaller size of pillar creates stress in the roof of gateroads which increases the cost of support and probability of rockburst in gateroads. Furthermore, pillars would be the source of rockburst as stress concentrates on them.

\section{The strategy}

From the analysis above if there is such a strategy that gateroad can be driven in de-stressed zone or at least in virgin cover load zone (unfortunately, this leads to low recovery) then it would be favorable for application. From the Fig. 1 there are only two sections located in destressed zone, one is section I, the other one is in the goaf. However, it is unrealistic to excavate a roadway directly in the goaf. This led to the creation of the strategy termed "longwall mining with split-level gateroads" (LMSG) or "Split-Level Longwall Mining"[7], which is an innovative advance for longwall mining. Fig. 3 is the system of a typical top coal caving of LMSG in flat or nearly flat coal seam. As shown in Fig. 3, gateroads on both ends of the middle panel are located in different levels (split-level) with the headgate 1 driven along the floor while the tailgate 2 driven along the roof forming a gradually elevated section 5 on the right end of the panel. This section is elevated by adjusting the inclination of each pan, shield and other machines. Headgate 3 of the successive panel is driven along the floor, and under the edge of the mined-out area after the excavation of the middle panel in the same manner how the headgate 1 is driven. Corresponding operations for LMSG are unique and termed "triple sections mining technology" (TSMT) ${ }^{[8]}$.

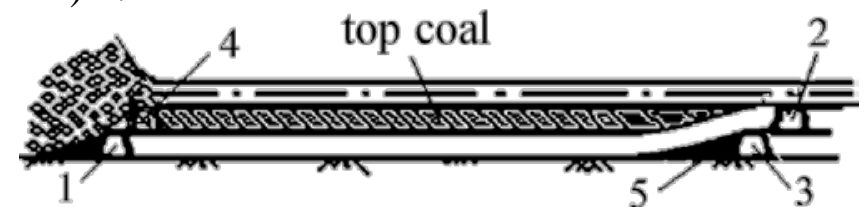

1-Headgate; 2-Tailgate; 3-Headgate of successive panel; 4-Tailgate of previous panel; 5—Triangular pillar

Fig. 3 The system of a typical LMSG top coal caving in a flat or nearly flat coal seams

Since the headgate is located in de-stressed zone, requirement for roof supports is less. What's more, the coal bumps and rockbursts in the gateroad can be effectively avoided as no stress concentration occurs in this de-stressed area, as shown in Fig. 4. 


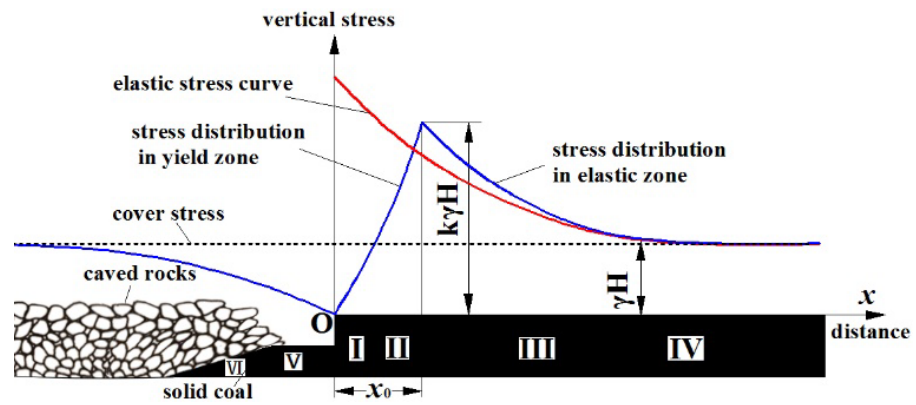

Fig. 4 Stress distribution after excavation of a panel using LMSG

The headgate is now driven in section $\mathrm{V}$, the vertical stress as we can see is far less than original overburden pressure. As solid triangular coal loss is located in negative half axis, thus it is termed "negative coal pillar" as in conventional longwall mining the pillar is positive pillar. Most importantly, the coal loss is tremendously reduced as originally " $T$ " shape coal loss is now triangular.

LMSG was not only exclusively used in medium-thick, thick or ultra-thick coal seams. Actually, with the development of tunneling technology, rock gate roads can now be driven at relatively lower cost, therefore the application of LMSG in thin coal seam can also achieve high yield and high efficiency. For many cased in China, tailgates are driven in immediate roof or main roof rock bed.

\section{Case study site}

No. 2 \# coal seam in Zijin coal mine is located in the north of Huoxi coal field, center of Shanxi Province. The height of coal seam is $2.46 \mathrm{~m}$ on average, cover depth is $420 \mathrm{~m}$, roof strata in ascending order are $3.6 \mathrm{~m}$ sandy mudstone, $5.4 \mathrm{~m}$ mudstone and $2.5 \mathrm{~m}$ siltstone, while the floor strata in decending order are $1.48 \mathrm{~m}$ siltstone, $5.7 \mathrm{~m}$ fine sandstone and $3.25 \mathrm{~m}$ sandy mudstone.

Two boreholes were drilled underground, $13 \mathrm{~m}$ borehole was drilled in roof strata of headgate and $10 \mathrm{~m}$ borehole in floor strata; $10.3 \mathrm{~m}$ borehole was drilled in the roof strata and $10 \mathrm{~m}$ borehole in the floor strata; Fig. 5 (a) and (b) shows the borehole samples. The samples were sent to the lab and processed, samples are cylindrical with diameter of $50 \mathrm{~mm}$, aspect ratio of 2:1. Fig. 5 (c) shows the processed rock samples. Then mechanical properties such as uniaxial compressive strength, tensile strength, shearing strength, etc. were to be determined as shown in Fig. 5 (d) and (e). The mechanical properties of coal seam, roof and floor strata were obtained as shown in Table 1.

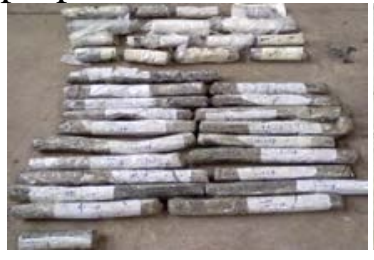

(a) Sealed drill core

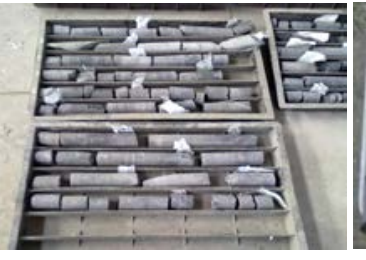

(b) Unsealed drill core (c) Processed samples

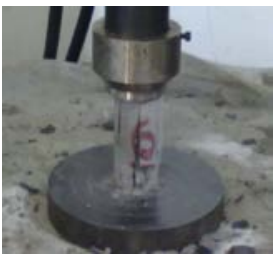

(d) UCS test

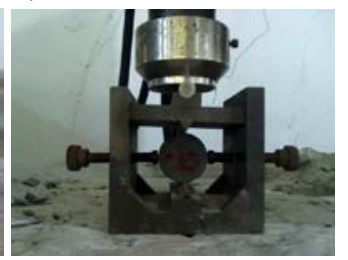

(e)Splitting tensile test

Fig. 5 Borehole samples and mechanical tests

Table 1 The mechanical properties of coal seam, roof and floor

\begin{tabular}{ccccccc}
\hline Rock type & $\begin{array}{c}\text { Height } \\
(\mathrm{m})\end{array}$ & $\begin{array}{c}\text { Height Sum } \\
(\mathrm{m})\end{array}$ & $\begin{array}{c}\text { Density } \\
\left(\mathrm{kg} / \mathrm{m}^{3}\right)\end{array}$ & $\begin{array}{c}\text { Compressive strength } \\
(\mathrm{MPa})\end{array}$ & $\begin{array}{c}\text { Elastic modulus } \\
(\mathrm{GPa})\end{array}$ & $\begin{array}{c}\text { Poisson Ratio } \\
\lambda\end{array}$ \\
\hline Gritstone & 9.89 & 34.02 & 2430 & 36.6 & 23 & 0.28 \\
Siltstone & 2.5 & 24.13 & 2460 & 40.6 & 35 & 0.28 \\
mudstone & 5.4 & 21.63 & 2500 & 20.6 & 23 & 0.28 \\
$\begin{array}{c}\text { Sandy } \\
\text { mudstone }\end{array}$ & 3.6 & 16.23 & 2240 & 22.8 & 32 & 0.28 \\
2\# Coal seam & 2.2 & 12.63 & 1480 & 10.5 & 23 & 0.28 \\
Siltstone & 1.48 & 10.43 & 2460 & 40.6 & 15 & 0.35 \\
Sandy & 3.25 & 8.95 & 2240 & 22.8 & 35 & 0.25 \\
mudstone & 5.7 & 5.7 & 2500 & 44.6 & 23 & 0.28 \\
Fine sandstone & 5 & & &
\end{tabular}


As the average thickness of the No. 2 \# coal seam in Zijin coal mine is only $2.46 \mathrm{~m}$, top coal caving of LMSG is not applicable. Fortunately however, the mechanical properties of roof and floor strata indicate that they are relatively soft as we can see from Table 1, in order to use LMSG, tailgate was driven in the roof and part of the headgate in the floor.

\section{Physical modelling}

A large-scale physical plane-strain model test was conducted with the dimension of $3000 \mathrm{~mm} \times 3000$ $\mathrm{mm} \times 200 \mathrm{~mm}$ (length $\times$ height $\times$ thickness) as shown in Fig. 6 (a). CM-2B type static strain indicator was used to collect strain by stress boxes pre-inbuilt in the model consisting of BE120-3AA type resistance strain gauge, copper ring and copper sheet. Strains measured by the stress boxes were converted to stress value. In order to obtain stress distribution of the headgates, stress sensors coupled with dynamic strain indicators and data auto-collecting computer system are installed in the roof of the coal seam along the model. Stress boxes and related equipment are shown in Fig. 6 (b) and Fig. 6 (c) respectively. Some key steps are shown in Fig. 7. To see the stress distribution of the gateroads, stress curves are plotted in Fig. 8.

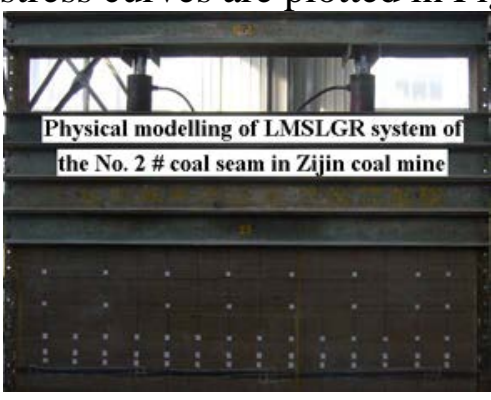

(a) Physical model

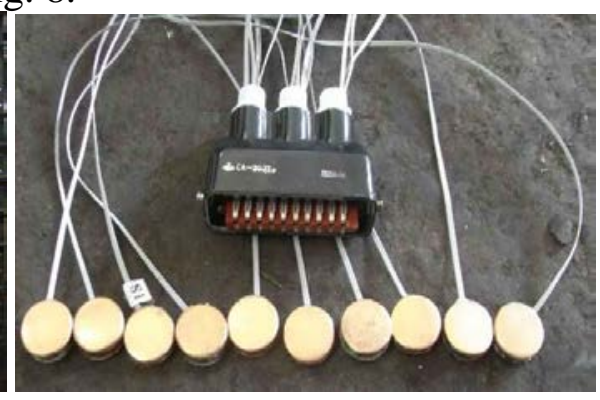

(b) Stress boxes

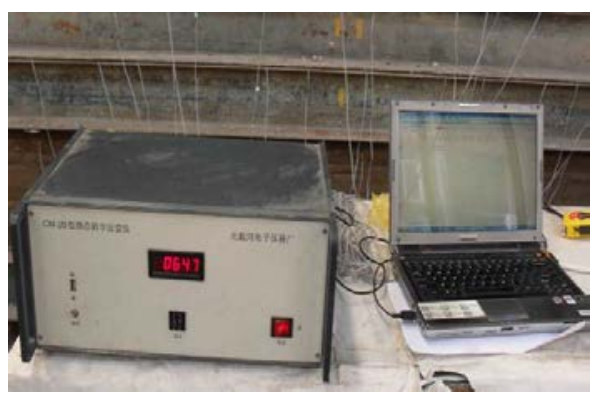

(c) Stress processing equipment

Fig. 6 Physical modelling and apparatus

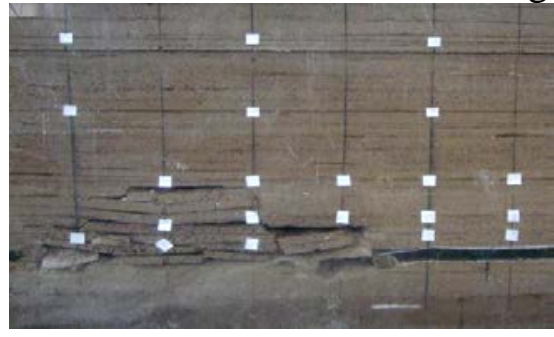

(a) Excavation of the first panel

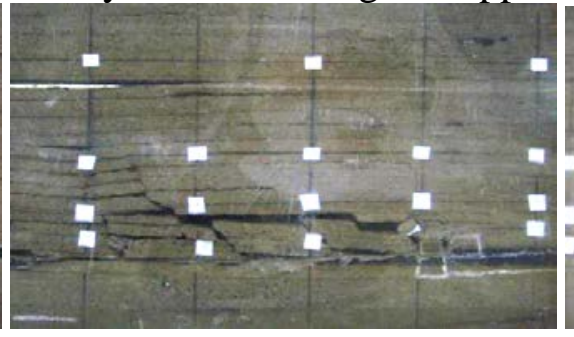

(b) Excavation of the second panel

Fig. 7 Key steps

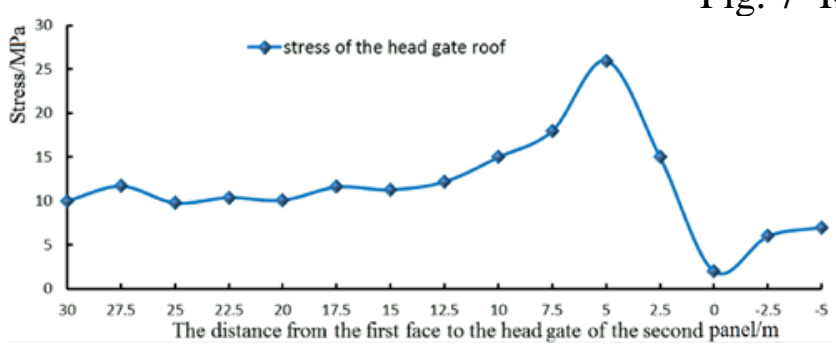

(a) During the extraction of the second panel

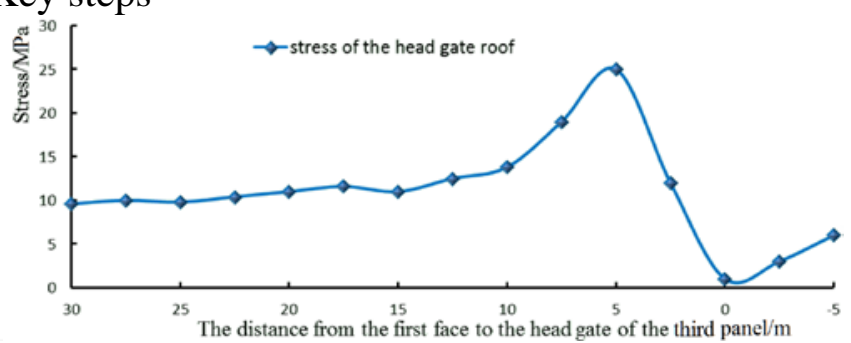

(b) During the extraction of the third panel

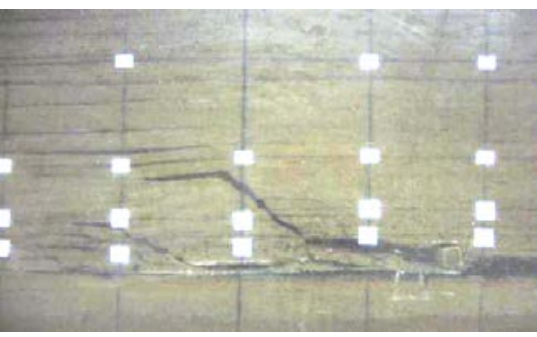

(c) Excavation of the third panel

Fig. 8 Stress curves

As we can see in Fig. 8, the stress of the headgate roof changes with the distance from the previous working face to the headgate of the subsequent penal. As face advances forwards, the stress gradually picks up. Then it increases exponentially reaching peak abutment pressure up to 4 times of the in-situ stress when the face is $5 \mathrm{~m}$ away from the face. Then it falls sharply to between $5 \sim 0 \mathrm{~m}$. While within the range $0 \sim-5 \mathrm{~m}$, which means that the face has advanced past the headgate overhead, vertical pressure reduces to far below the pre-mining pressure and gradually increases toward the goaf area. As a consequence, the headgate excavated in this section will suffer from very low pressure which is favorable for gateroad support and maintenance. 


\section{Conclusions}

It demonstrates clearly in this paper that panel layout plays a critical role in improving stress environment for gateroads in longwall mining. Since the invention of LMSG, it has been applied in a number of coal mines in China and obtained great profits. It is an innovative strategy which will play an important role in coal industry.

\section{Acknowledgments}

This work was financially supported by the Fundamental Research Funds for the Central Universities (No. 2011YZ10) and China Scholarship Council (No. 201506430011).

\section{References}

[1] Shen B, King A, Guo H. Displacement, stress and seismicity in roadway roofs during mining-induced failure. Int J Rock Mech Min Sci 2008;45:672-88

[2] Lawrence W. A method for the design of longwall gateroad roof support. Int J Rock Mech Min Sci 2009;46:789-95.

[3] Mahdi Shabanimashcooln, Charlie C. Li. Numerical modelling of longwall mining and stability analysis of the gates in a coal mine. Int. J. Rock Mech. Min. Sci. 2012;51:24-34

[4] Forrest P. Schumachera, Eunhye Kim. Modeling the pipe umbrella roof support system in a Western US underground coal mine. Int. J. Rock Mech. Min. Sci. 2013;60: 114-124

[5] H. Yavuz.An estimation method for cover pressure re-establishment distance and pressure distribution in the goaf of longwall coal mines. Int. J. Rock Mech. Min. Sci. 2004;41:193-205

[6] Syd S. Peng. Topical areas of research needs in ground control - A state of the art review on coal mine ground control. Int J Mining Sci Technol 2015; 25 (1):1-6.

[7] Jingli Zhao. Full-extraction longwall mining with split-level gate roads (FELMSG) in thick coal seams. [P]. China Patent: ZL98100544.6.

[8] Jingli Zhao. Triple sections mining technology (TSMT) in FELMSG in thick coal seams. [P]. China Patent. 2004100395750n 